\title{
Simulation of freezing and melting of soil on the northeast Tibetan Plateau
}

\author{
XIA Kun ${ }^{1,2,3^{*}}$, LUO Yong ${ }^{2,4,5} \&$ LI WeiPing ${ }^{2}$ \\ ${ }^{1}$ Institute of Atmospheric Physics, Chinese Academy of Sciences, Beijing 100029, China; \\ ${ }^{2}$ National Climate Center, China Meteorological Administration, Beijing 100081, China; \\ ${ }^{3}$ Graduate University of Chinese Academy of Sciences, Beijing 100049, China; \\ ${ }^{4}$ Center for Earth System Science, Tsinghua University, Beijing 100084, China; \\ ${ }^{5}$ Key Laboratory of Earth System Numerical Simulation, Ministry of Education, Beijing 100084, China
}

Received January 25, 2011; accepted April 27, 2011

\begin{abstract}
Using observational data spanning the period from February to December 2009 and recorded at the Suli station in Qinghai Province, the land-surface model CLM3.0 was employed to simulate the freezing and melting of soil. The results indicate that the simulated soil temperature is higher than the observed soil temperature and the ultimate thawing date is earlier than the observed date during the melting period. During the freezing period, the simulated soil temperature is lower than the observed soil temperature and the ultimate freezing of the deep soil is earlier than that observed. Overall, the simulation of freezing is better than that of melting, and the simulation of a shallow layer is better than that of a deeper layer. In the original CLM3.0, it is assumed that frozen soil begins to melt when the soil temperature exceeds $0^{\circ} \mathrm{C}$, which is inconsistent with observations. The critical freeze-thaw temperature was calculated according to thermodynamics equations and the freeze-thaw condition was modified. In this work, the melting rate for frozen soil was reduced using the modified scheme, and the simulated soil temperature was lowered. Meanwhile, the refreezing of soil during the melting season was well simulated and more closely matched observations. Additionally, it was found that the rates of melting and freezing differ, with the former being slower than the latter, but refreezing during the melting season is rather quick.
\end{abstract}

freezing, thawing, freeze-thaw critical temperature, numerical simulation

Citation: Xia K, Luo Y, Li W P. Simulation of freezing and melting of soil on the northeast Tibetan Plateau. Chinese Sci Bull, 2011, 56: 2145-2155, doi: 10.1007/s11434-011-4542-8

The cryosphere is an important component of the climate system, which consists of five components: the atmosphere, the hydrosphere, the cryosphere, the land surface and the biosphere. It is the most sensitive component and usually has the most direct influence on the climate system. Therefore, it is considered an important factor influencing the interaction between the five elements. Establishment of the Climate and Cryosphere Project (CLiC) has meant that research on the cryosphere has become a new research hotspot internationally [1] (http://www.climate-cryosphere.org/

*Corresponding author (email: xiakun@cma.gov.cn) en/). Except for the poles, frozen soil is mainly distributed in high-elevation regions, such as the Qinghai-Tibetan Plateau, which are sensitive to climate change. The variation in unique hydrothermal characteristics plays an important role in the energy exchange between the land and atmosphere, and affects carbon circulation and weather-climate systems. Freezing and thawing of soil are the most remarkable physical characteristics of the plateau [2]. Research has demonstrated that freezing and thawing on the Qinghai-Tibetan Plateau have good relationships with summer precipitation [3]. Land-atmosphere interactions over the plateau need to be studied to improve the predictability of numerical models.

There have been studies on the relationship between 
climate change and frozen soil [4-8], but few works about the effect of the change of frozen soil on climate change in China. It is a great challenge to study the complex physical mechanism of frozen soil, especially the parts associated with climate change [9]. The simulation of a long time sequence of land-surface processes on the Qinghai-Tibetan Plateau is meaningful work. The biggest limitation has been a lack of a wide range of observation data, which even prevents the development of the frozen soil model. Until the late 1990s, attention had been given to frozen soil parameterization in land-surface models [10-14], and a corresponding module has been added to land-surface models. In China, Li and Sun [15] developed a frozen soil hydrothermal transfer model in which total enthalpy and total soil quality are chosen as predictands, and the instability arising from uncertainty in the rate of phase change was effectively avoided. Two atmospheric experiments were carried out in 1979 and 1998 on the Qinghai-Tibetan Plateau, the data collected during the two experiments provide the necessary condition for land-atmosphere study on the plateau $[16,17]$. However, because the observation data were concentrated in the period from May to September, they do not contribute greatly to the simulation of freezing and thawing on the plateau.

By comparing more than 20 representative land-surface models, the Program for Inter-comparison of Land Surface Parameterization Schemes (PILPS) found that models usually have apparent distinctions for the simulation of energy and water exchange occurring at the land-atmosphere interface when forced by the same atmospheric conditions. Many models provide good results for humid areas with homogeneous vegetation, but more work is needed for areas of snow, frozen soil, desert, and inhomogeneous land surfaces to improve simulation results [18-20]. The Community Land Model (CLM) is one of the best land-surface models. Many numerical and verification experiments have been carried out for the model used in this study; i.e. adaptability of the model to Asian monsoon areas [21], plateau areas of sparse vegetation, paddy fields [22], typical climate regions of China [23], and desert [24]. However, there have been few experiments for frozen areas. Xin et al. [25] examined the applicability of the CLM to northwestern arid areas and the western Qinghai-Tibetan Plateau using short-range observation data for summer. Wang et al. [26] and Luo et al. [27] demonstrated the model's applicability to the western and central Qinghai-Tibetan Plateau, respectively. However, no work has been done for the northern Qinghai-Tibetan Plateau.

In this paper, observation data spanning the period from February 1 to December 31, 2009, and recorded at the Suli station located in northeastern Qinghai Province were adopted for a single-point numerical simulation. The performance and applicability of CLM3.0 were examined by comparing with soil temperature and moisture observations. Furthermore, the freeze-thaw condition of the model was modified.

\section{Model and data}

\subsection{Model introduction}

The CLM was developed by the National Center for Atmospheric Research and is based on the Biosphere-Atmosphere Transfer Scheme (BATS), the Institute of Atmospheric Physics Land Surface Model (IAP94) and the Land Surface Model (LSM). The CLM was constructed with uniformly distributed vertical soil layers, at most five snow layers, and one vegetation layer. The flux was calculated separately for different underlying surfaces by considering inhomogeneity on the sub-grid scale of land-surface characteristics, vegetation types, hydraulics and thermodynamic characteristics of different soil types, and the homogeneity of atmospheric forcing acting on all underlying surfaces. The flux required by the atmosphere is obtained by averaging the sub-grid quantities weighted by all vegetation types.

The atmospheric forcing data for the offline CLM3.0 experiment are data for temperature, pressure, humidity, wind speed, precipitation and downward longwave and shortwave radiation. No consensus has been reached on how to divide the soil layers in the CLM, but it is agreed that the shallow soil layer has a larger moisture gradient [28]; therefore, to precisely describe the variation in soil moisture, shallow soil has more layers than deeper soil [29]. Division of the vertical soil layers follows an exponential distribution. The depths of soil layers are $0.71,2.79,6.23$, $11.89,21.22,36.61,61.98,103.80,172.76$ and $286.46 \mathrm{~cm}$; a detailed description of the CLM is given in [30].

The version of the CLM used in this study is CLM3.0. The difference between CLM3.0 and CLM4.0 is the soil freezing condition. CLM3.0 considers that all liquid water freezes when the soil temperature is below $0^{\circ} \mathrm{C}$, whereas CLM4.0 considers that liquid water and ice can coexist when the soil temperature is below $0^{\circ} \mathrm{C}$. Only when the liquid-water content is greater than the maximum allowable liquid-water content does the excess freeze. Obviously the latter consideration is more realistic. Therefore, the freezethaw condition is replaced with the equivalent part of CLM4.0 [31]. The freeze-thaw equation can be written as

$$
\begin{array}{ll}
T>T_{\text {frz }} \text { and } \theta_{\mathrm{ice}}>0 & \text { for the thawing period and } \\
T>T_{\text {frz }} \text { and } \theta_{\text {liq }}>\theta_{\text {liq,max }} & \text { for the freezing period. }
\end{array}
$$

When the soil freezes or thaws, the soil temperature is $T_{\text {frz }}$, where $\theta_{\text {liq,max }}$ is the maximum liquid-water content when the soil temperature is below the freezing point; $\theta_{\text {liq, max }}=\theta_{\text {sat }}\left\{\frac{10^{3} L_{\mathrm{f}}\left(T-T_{\mathrm{fiz}}\right)}{g T \psi_{\text {sat }}}\right\}^{-1 / b}$. The freezing point of liquid water $T_{\text {frz }}$ is $273.16 \mathrm{~K}$. $\theta_{\text {sat }}$ is the saturated soil water content, $\theta_{\mathrm{liq}}$ is the soil volume water content, $\theta_{\text {ice }}$ is the soil volume ice content, and $\psi_{\text {sat }}$ is the saturated matric water potential in units of millimeters. Latent heat fusion of $L_{\mathrm{f}}$ is a constant 
with a value of $0.336 \times 10^{6} \mathrm{~J} \mathrm{~kg}^{-1}$.

\subsection{Data preparation}

Simulations were performed for the Suli station, which is located at $38.42^{\circ} \mathrm{N}, 98.30^{\circ} \mathrm{E}$, northeast of Qinghai Province, and belongs to the upper reaches of the Shule River at an elevation of $3802 \mathrm{~m}$. The data span a period from February 1 to December 31, 2009. The land surface is mainly covered by alpine meadow. The soil type is sandy loam. The area has a notable cold-plateau semi-arid climate. A meteorological observation tower with height of $10 \mathrm{~m}$ was built at Suli with meteorological variables (10-min air temperature, pressure, humidity, and wind speed) recorded at four heights $(2,5,7.5$ and $10 \mathrm{~m})$. Precipitation was collected by a T_200B rain gauge. Soil temperature was measured at depths of $5,10,30,50$ and $70 \mathrm{~cm}$. Soil moisture was observed at 20,40 and $60 \mathrm{~cm}$, and soil heat flux at depths of 5 and $10 \mathrm{~cm}$. In addition, a vortex dynamic radiometer was set on the meteorological tower to obtain downward longwave radiation from the Sun, upward shortwave radiation reflected by the land surface and upward longwave radiation with a time interval of 30 minutes. All data were used for driving or validating the model.

The observations made at a height of $2 \mathrm{~m}$ were used as atmospheric forcing data and this height was set as the base of the atmosphere in the model. Considering the sensitivity of the model to initial values, a 2-year spin-up was carried out at a single point. To compare simulations and observations more conveniently, the output was linearly interpolated to depths of 20,40 and $60 \mathrm{~cm}$.

\section{Simulations and analysis}

The CLM3.0 model was employed to simulate the soil water and thermal processes at the Suli station of Qinghai Province with observation data spanning the period from February 1 to December 31, 2009. This test is referred to as the control test and is intended to validate the model's ability to simulate the exchange of soil water and heat in seasonally frozen areas. Because a change in ice content in soil affects soil water and heat properties, and influences the simulation of soil temperature and moisture, this work mainly examines simulations of soil temperature and moisture for individual layers.

\subsection{Soil temperature}

The accuracy of the calculated soil temperature in the landsurface model usually affects energy and material exchange between the land surface and atmosphere, and further affects the performance of the atmospheric model. Therefore, the simulation of soil temperature is important [32].

The air temperature at a height of $2 \mathrm{~m}$ rises slightly from
February 2009 and then falls to about $-20^{\circ} \mathrm{C}$ by mid-March. Afterward, although there are several insignificant temperature declines, the entire temperature tendency is to rise, especially from late March to early April during which time the air temperature increases from $-10^{\circ} \mathrm{C}$ to above $0^{\circ} \mathrm{C}$, and it remains above $0^{\circ} \mathrm{C}$ from June. The incident shortwave radiation reduces as winter arrives, and the air temperature decreases rapidly from $3^{\circ} \mathrm{C}$ to $-10^{\circ} \mathrm{C}$ in early October (Figure 1(a)). The tendency of the temperature change for soil close to the surface is the same as that of the air temperature at a height of $2 \mathrm{~m}$, and the simulated soil temperature at 20 $\mathrm{cm}$ depth is similar to observations (Figure 1(b)). However, for deeper soil layers, there is a lag in the temperature variation. The observed soil temperatures at 40 and $60 \mathrm{~cm}$ rise and exceed $0^{\circ} \mathrm{C}$ on May 10 and June 5, respectively. The simulated ultimate melting dates (i.e. dates on which the ice in soil completely melts) for all soil layers are earlier than those observed, and the deeper the soil, the greater the difference, which is about a month in the case of $60 \mathrm{~cm}$ depth (Figure 1(c), (d)). The simulated date on which the soil begins to freeze is much the same as the observed date for a depth of $20 \mathrm{~cm}$, but it is further in advance for deeper soil, being about 15 days ahead for soil at $60 \mathrm{~cm}$ depth (Figure 1(d)).

In an experiment carried out by $\mathrm{Xu}$ [33], it was found that the freezing temperature and thawing temperature of loess, sandy soil, red soil, clay soil and loamy soil are all below $0^{\circ} \mathrm{C}$, which means that all these soils begin to melt at temperatures lower than $0^{\circ} \mathrm{C}$. In CLM3.0, it is considered that frozen soil begins to melt only when the temperature is higher than the freezing point. No melting occurs in early March when the modeled temperature is below $0^{\circ} \mathrm{C}$, whereas in reality, the soil has begun to melt and the soil liquid-water content increases slightly (Figure 2). The melting of ice absorbs energy from the soil and prevents a rise in soil temperature; however, the simulated soil has not thawed, the energy from the lower soil layer increases the soil temperature, and the simulation of soil temperature from March to April is thus higher than the observed soil temperature. After the simulated soil temperature reaches $0^{\circ} \mathrm{C}$, and the air temperature rises, the simulated frozen soil melts completely by mid-April, and the predicted melting date is earlier than the observed date. When the simulated soil thaws and the observed soil does not, the difference between simulation and observations is great. For example, in early May, the difference in soil temperature at $40 \mathrm{~cm}$ depth is about $4^{\circ} \mathrm{C}$.

In summary, CLM3.0 simulates well the variations in soil temperature in all layers. Simulation of freezing is better than that of thawing, and simulations at shallower depths are better than those at deeper depths. However, the simulated thawing is too fast, which leads to a higher temperature and earlier thawing time than what is observed. During the freezing period, the simulated temperature of deeper soil is lower than the observed temperature, and the freezing 

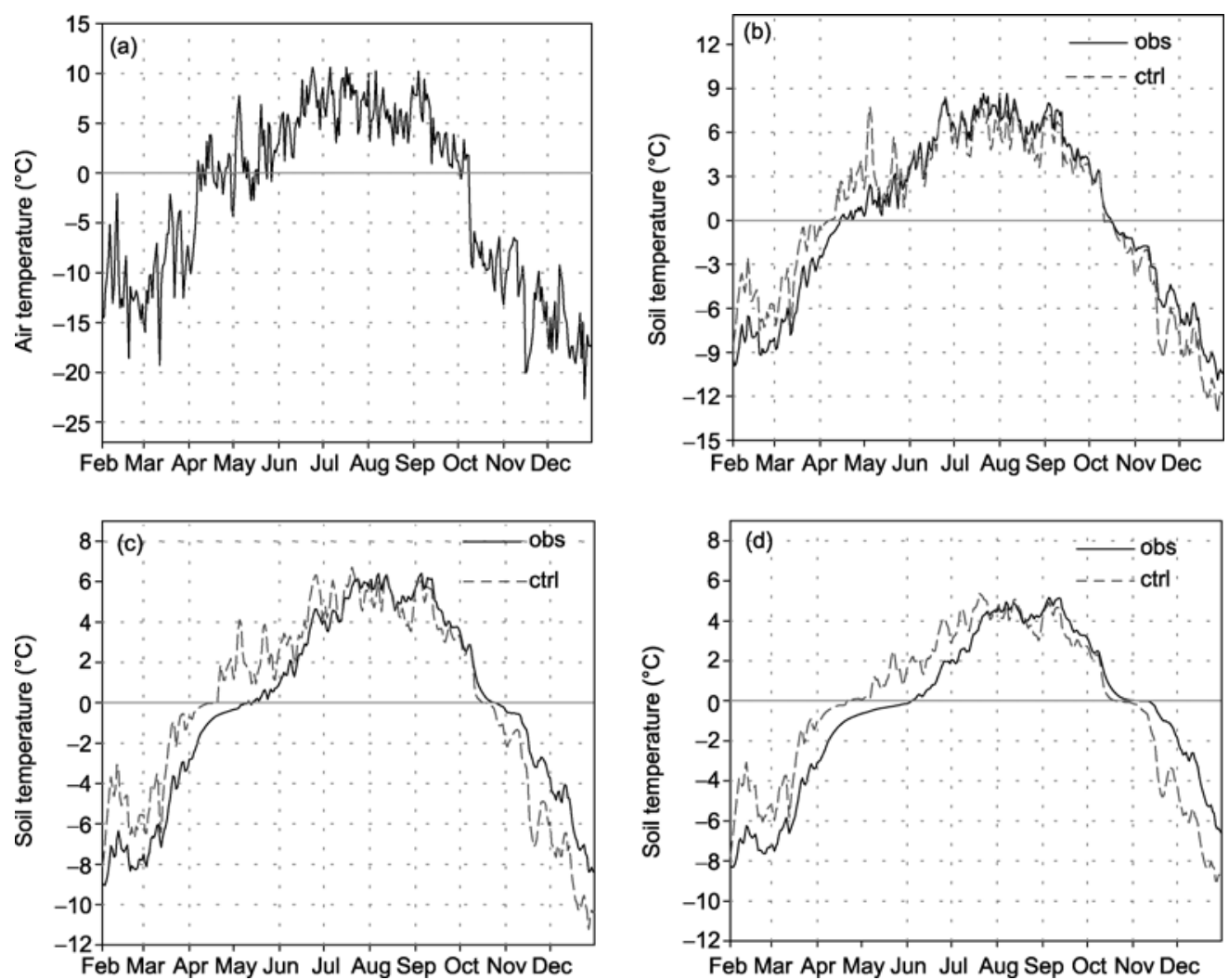

Figure 1 Observed temperature at a height of $2 \mathrm{~m}$ (a) and comparison of the simulated soil temperature (dashed) with observations (solid line) at depths of $20 \mathrm{~cm}$ (b), $40 \mathrm{~cm}$ (c) and $60 \mathrm{~cm}$ (d).
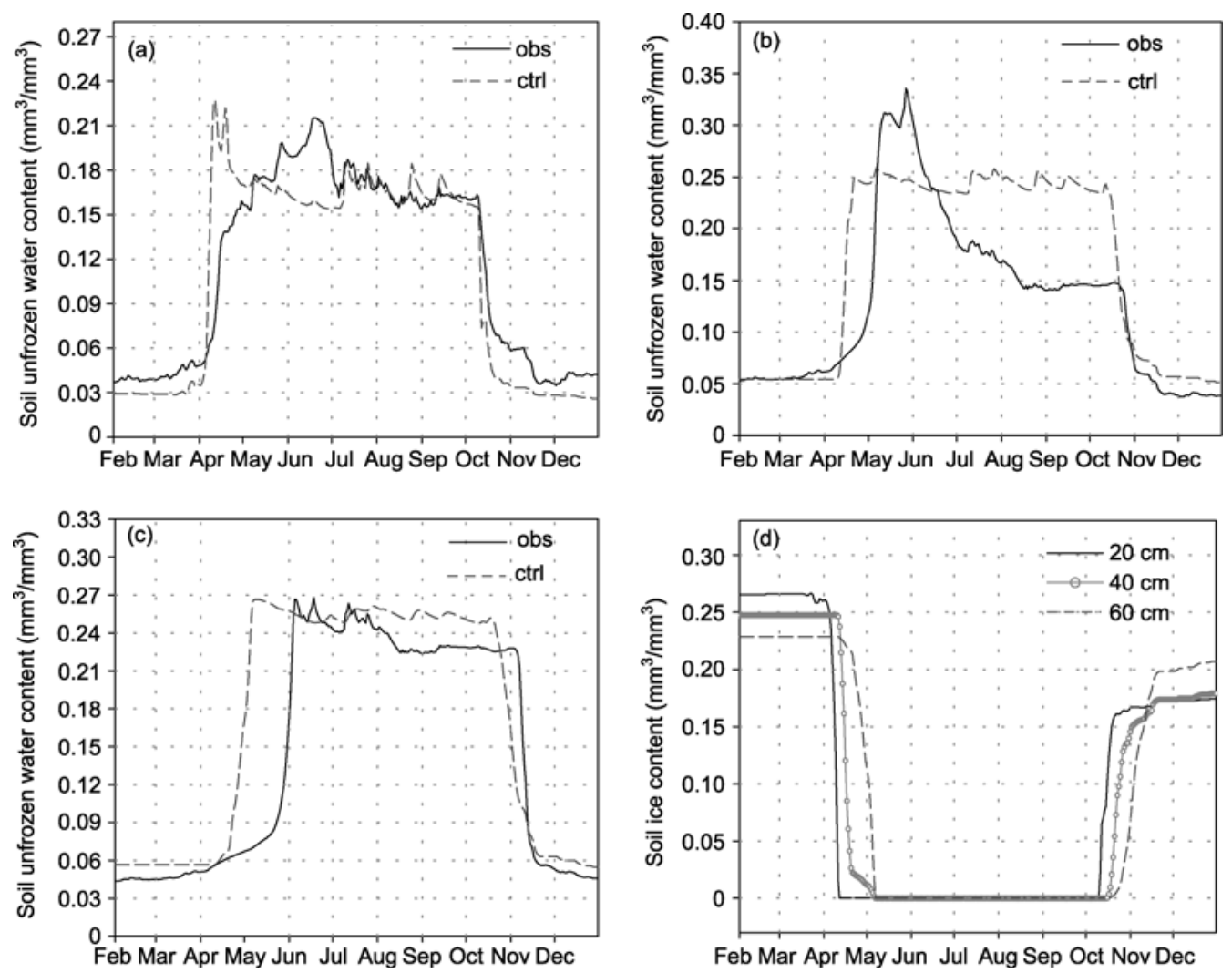

Figure 2 Comparison of the simulated soil liquid-water content (dashed) with observations (solid line) at depths of $20 \mathrm{~cm}$ (a), $40 \mathrm{~cm}$ (b) and $60 \mathrm{~cm}$ (c), and simulated soil ice content (d) in the three layers. 
time is earlier than the observed time.

\subsection{Soil moisture}

Soil moisture plays an important role in the interaction of land and atmosphere, affecting the regional climate by influencing runoff, albedo, surface sensible heat flux and latent heat flux [34]. It is an important variable for model estimations.

The simulated soil liquid-water content remains unchanged during February and April 2009 (Figure 2(a), (b), (c)). The soil begins to melt from the surface to deeper layers when it satisfies the frozen-soil melting condition, at which time the soil ice content decreases rapidly. For example, the ice content in soil at $20 \mathrm{~cm}$ depth decreases from a fractional volume of 0.27 to 0.0 over several days in early April. The ultimate melting times for 20 and $60 \mathrm{~cm}$ depths have lags of about 1 month, which reflects the spread of energy over time from the surface to deeper levels. In reality, the soil liquid water content begins to increase at the beginning of March; for example, the soil liquid-water content at $60 \mathrm{~cm}$ depth remains at 0.045 from February to early March, and gradually increases to about 0.08 by late May (Figure 2(c)). Meanwhile, the soil temperature increases from $-6^{\circ} \mathrm{C}$ to $-1{ }^{\circ} \mathrm{C}$ (Figure $1(\mathrm{c})$ ). This indicates that the soil began melting when the soil temperature was below $0^{\circ} \mathrm{C}$. Obviously, the model setting of the thawing condition conflicts with the observation. The simulated melting starts late but has a high melting rate, and finishes earlier than what is observed. The simulation of the freezing is better than that of the thawing.

\section{Model modifications}

It was seen from the control test that the thawing and freezing tendencies are well simulated, but CLM3.0 arbitrarily specifies that the soil melts only when the soil temperature is higher than $0^{\circ} \mathrm{C}$, which is not in agreement with observations [33]. An actual freezing-thawing process is a slowly and continuously changing process, and there is no fixed freeze-thaw critical temperature. The relationship between the soil water content and temperature should be determined by the thermodynamic equilibrium relationship between the soil water potential and temperature and the inherent characteristics of soil hydraulics. Therefore, the method of calculating the soil freezing-thawing critical temperature used by Sun and Li [15] was adopted in this study to replace the unreasonable hypothesis used in CLM3.0.

When ice is present, the soil water potential remains in equilibrium with the vapor pressure over pure ice. According to the Clausius-Clapeyron equation, the functional relation between the soil water matrix potential $\psi(\mathrm{mm})$ and soil temperature is

$$
\psi(T)=\frac{10^{3} L_{\mathrm{f}}\left(T-T_{\mathrm{frz}}\right)}{g T},
$$

where $T$ and $T_{\text {frz }}$ are the soil temperature and freezing point $(\mathrm{K})$, respectively, $L_{\mathrm{f}}$ is the latent heat of fusion $\left(\mathrm{J} \mathrm{kg}^{-1}\right)$, and $g$ is gravitational acceleration $\left(\mathrm{m} \mathrm{s}^{-2}\right)$.

Spaans and Baker [35] demonstrated that freezingthawing processes are similar to drying-wetting processes with regard to the dependence of the soil matric potential on the liquid-water content. The soil matric potential as a function of liquid-water content is

$$
\psi\left(\theta_{\text {liq }}\right)=\psi_{\text {sat }}\left(\frac{\theta_{\text {liq }}}{\theta_{\text {sat }}}\right)^{-b},
$$

where $\psi_{\text {sat }}$ is the saturated soil matrix potential, $\theta_{\text {sat }}$ and $\theta_{\text {liq }}$ are porosity and the partial volume of liquid water, and $b$ is the Clapp-Hornberger parameter.

By equating $\psi(\mathrm{T})$ in eq. (1) to $\psi\left(\theta_{\mathrm{liq}}\right)$ in eq. (2), we derive the expression for the functional relation between the soil liquid-water content and freeze-thaw critical temperature:

$$
T_{\text {crit }}=\frac{10^{3} L_{\mathrm{f}} T_{\text {frz }}}{10^{3} L_{\mathrm{f}}-\psi_{\text {sat }}\left(\frac{\theta_{\text {liq }}}{\theta_{\text {sat }}}\right)^{-b} g},
$$

where $T_{\text {crit }}$ is the critical temperature at which soil water freezes or thaws. When the soil temperature is below/above $T_{\text {crit }}$, the soil water begins to freeze/thaw. Figure 3 is drawn from calculations using eq. (3). It is clearly seen that when the soil has low liquid-water content, sandy soil has the highest freeze-thaw critical temperature, loamy sand has the second highest, and the other soils have very low critical temperatures. The main reason is that sandy soil has macropores. Under certain suction conditions, a macropore can be easily drained. Therefore, the soil water content rapidly reduces as the suction increases. The pore size distribution is uniform in clayey soil and much water can be absorbed. Increasing the suction can only reduce the soil water content slowly. Thus, soil having low silt content has greater saturated soil water potential for the same liquidwater content [36]. From eq. (3), we know that the soil water matrix potential and soil temperature have an inverse relationship. Soil having lower silt content has a lower freeze-thaw critical temperature under the same liquid-water content conditions. The critical temperature rises gradually as the liquid-water content increases, but is always below the freezing temperature.

\subsection{Results obtained using the modified critical tem- perature for the melting of frozen soil}

The thawing critical temperature in CLM3.0 is replaced 


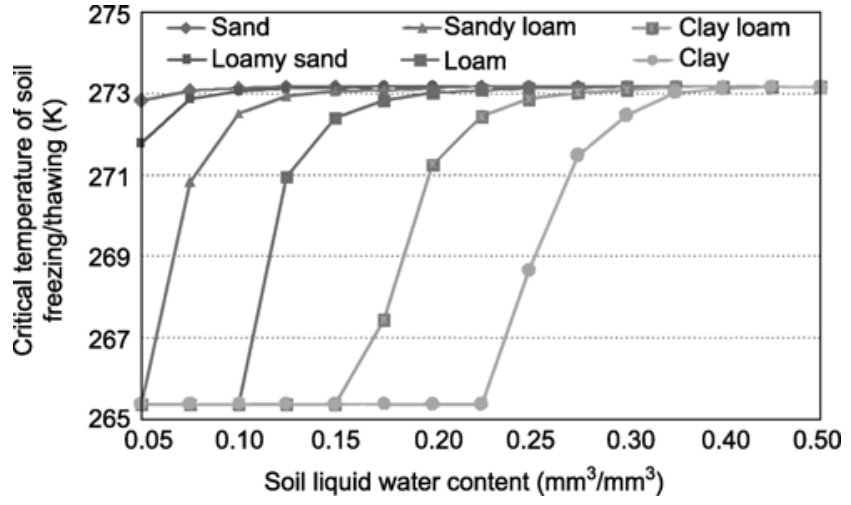

Figure 3 Freeze-thaw critical temperature versus the soil type and liquidwater content. with eq. (3) while the freezing conditions are kept the same:

When $T>T_{\text {crit }}$ and $\theta_{\text {ice }}>0$, soil melts and the soil temperature is $T_{\text {crit }}$ immediately after melting

This experiment is referred to as test 1 and is designed to examine the effects of the new critical temperature for thawing on the simulation.

Figure 4 shows that the new critical temperature for thawing has four main effects on the simulation. First, the simulated soil temperature during the thawing period is a little lower than it was previously, and much closer to observations (Figure 4(a)). Second, the simulated liquid-water content is reduced (Figure 4(b)). Third, the timing of the commencement of the melting of frozen soil is earlier, and the timing of ultimate melting is closer to that observed for
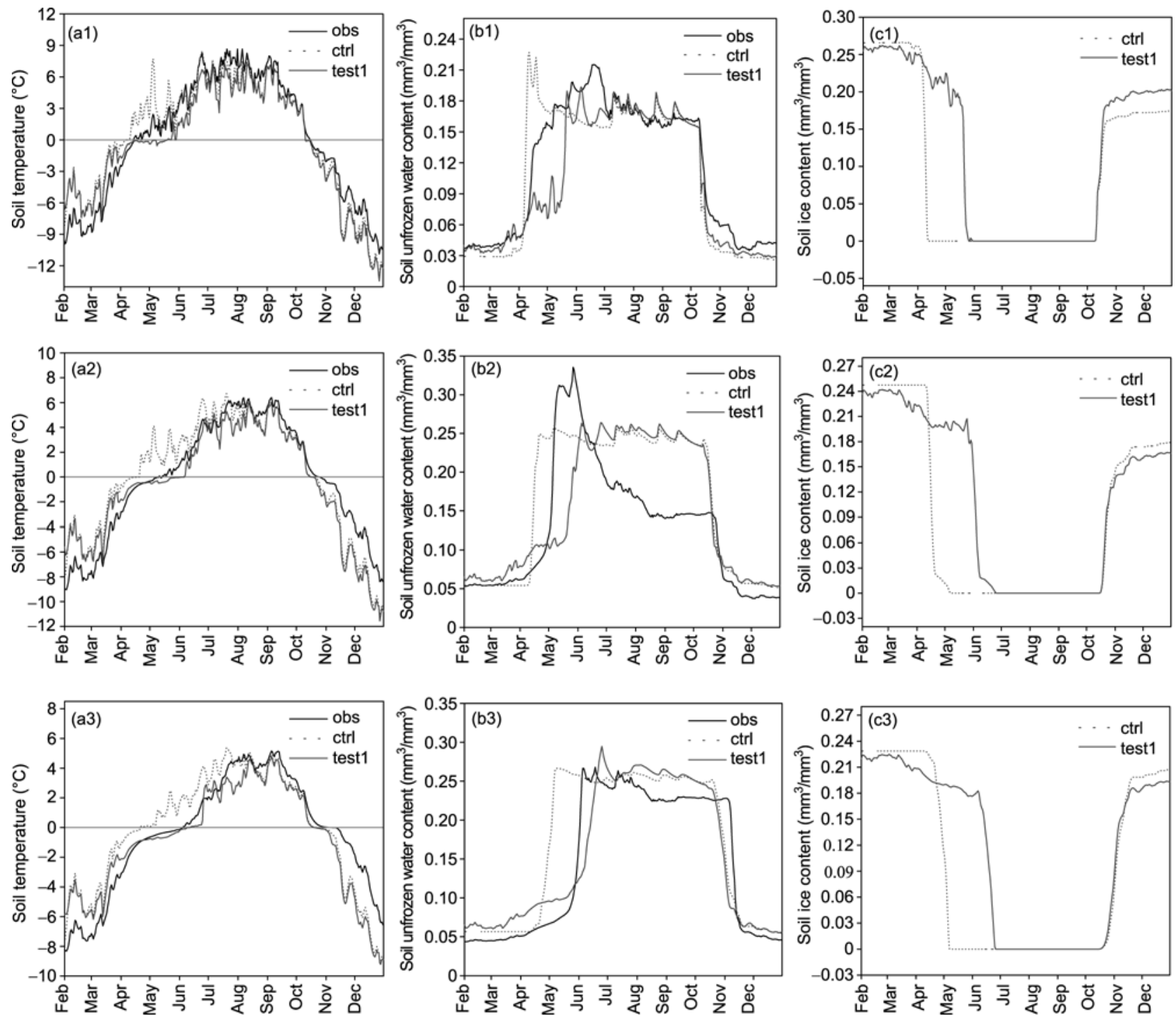

Figure 4 Comparison of observations (obs, heavy line) with soil temperature simulated with a change in the critical temperature for thawing (ctrl, dot line) and no change (test 1, fine line). The letter "a" in each figure represents the soil temperature, "b" the soil liquid-water content, and "c" the ice content in soil. Numbers 1, 2 and 3 represent the soil depths of 20, 40 and $60 \mathrm{~cm}$, respectively. 
the deeper frozen soil (Figure 4(c)). Fourth, there are several insignificant freezing events during the thawing period, which is similar to the actual soil freezing-thawing process. There are three main reasons for these improvements.

First, when the critical temperature for thawing is changed, frozen soil begins to melt at certain temperatures below $0^{\circ} \mathrm{C}$. Test 1 shows that frozen soil at $60 \mathrm{~cm}$ depth begins to melt in mid-March and the soil temperature is $-2^{\circ} \mathrm{C}$ at that time. The soil absorbs energy as it thaws, which prevents a rise in soil temperature. Reducing the thawing rate results in the simulation of the soil temperature better matching observations (Figure 4(a3)), and delays the melting time. This means that when the observed soil has melted, the simulated frozen soil is still melting in test 1 , and the simulated soil liquid-water content in test 1 is less than the observed content (Figure 4(b)).

Second, the soil temperature is equal to the freezing point after the phase change in CLM3.0, and the soil temperature is updated according to the difference in the energy cost between theory and practice (called net energy). Only when the water exists completely in liquid or solid form and the net energy does not equal zero can the energy surplus be used to change the temperature. If the net energy is zero, the soil temperature remains at the freezing point. When the critical temperature for thawing is changed, the soil temperature is replaced with eq. (3) after melting, which is lower than the freezing point and less than that in the control test. Therefore, the simulation of soil temperature during the melting phase is a little lower.

Third, for all soil types, when the soil temperature is below $0^{\circ} \mathrm{C}$, the maximum liquid-water content reduces as the temperature decreases [37]. By changing the critical temperature of thawing, ice in the soil melts when the soil temperature is below $0^{\circ} \mathrm{C}$, the liquid-water content increases and makes it easier for the soil temperature and moisture to meet the freezing conditions. Figure 4 shows that although the soil has a thawing tendency during February and April, there are several insignificant freezing events, indicating that the new critical temperature for thawing describes the thawing process well.

In summary, the change in the soil thawing condition reduces the thawing rate, and the simulation of soil temperature, soil liquid-water content and melting time is much closer to observations. However, the thawing of lower soil layers is slower than that observed while the performance is better for deeper layers.

\subsection{Results obtained using the modified freezing-thawing critical temperature for soil}

To examine the effect on simulation results, test 2 was carried out on the basis of test 1 but with the soil temperature after soil has frozen replaced with the new freeze-thaw critical temperature.

When there is freezing and thawing, the difference be- tween the soil temperature and freeze-thaw critical temperature is usually used to estimate the relationships between the excess or deficiency of energy and the amount of latent heat absorbed or released, and thus to determine the rate of change in ice content. Energy surplus has typically been used to update the soil temperature [38]. In test 1, it is supposed that when soil freezes, the temperature is $0^{\circ} \mathrm{C}$. Thus, $0^{\circ} \mathrm{C}$ was treated as the base point of the temperature update. In test 2, however, it is supposed that the frozen soil temperature is the freezing-thawing critical temperature and is lower than $0^{\circ} \mathrm{C}$. The base point of the temperature update thus decreases from $0^{\circ} \mathrm{C}$ to a certain temperature below $0^{\circ} \mathrm{C}$, which leads to the simulated temperature of soil with ice having a downward tendency. Thus, the simulated temperature during the thawing phase (February and April) is closer to observations but lower than observations during the freezing period (Figure 5). The main reason for the latter finding is that with decreasing shortwave radiation in winter, the soil temperatures of all layers decrease. When the soil temperature is below $0^{\circ} \mathrm{C}$ and the soil liquid-water content is greater than the maximum allowable liquid-water content, soil begins to freeze. Freezing releases latent heat, which limits the fall in soil temperature. However, as the soil freezes much faster in the model than in reality, soil is soon completely frozen. From then on, the soil temperature mainly varies with the air temperature, leading to a lower simulated soil temperature compared with the observed soil temperature during the freezing period. The root cause may be that the freezing rates for freezing and thawing periods greatly differ.

\subsection{Results obtained using the modified freezing rate}

In section 3.2, we deduced that the soil water has very different freezing rates for freezing and thawing periods. A sensitivity test (test 3 ) was designed to verify whether and to what degree a change in freezing rate affects the simulation results. In this test, the freezing rate remains the same during the thawing stage (February to June) while it is arbitrarily halved during the freezing stage (October to December).

Results show that the simulated soil temperatures of all layers obviously improve with the modified CLM3.0 and are closer to observations (Figure 6), while simulation of the soil liquid-water content does not vary greatly. The main reason is that the freezing rate is evidently lower during the freezing stage in test 3 . In other words, the rate of increase in ice content is less, which delays the ultimate freezing of soil water. This slows down the freezing of soil. The liquid-water content of soil decreases slowly, which prevents heat loss in soil. The heat capacity of water is greater than that of ice, and more liquid water in soil prevents the soil temperature decreasing quickly. Therefore, the simulated soil temperature is higher than that obtained in test 2 .

The most immediate effect of changing the soil freezing 

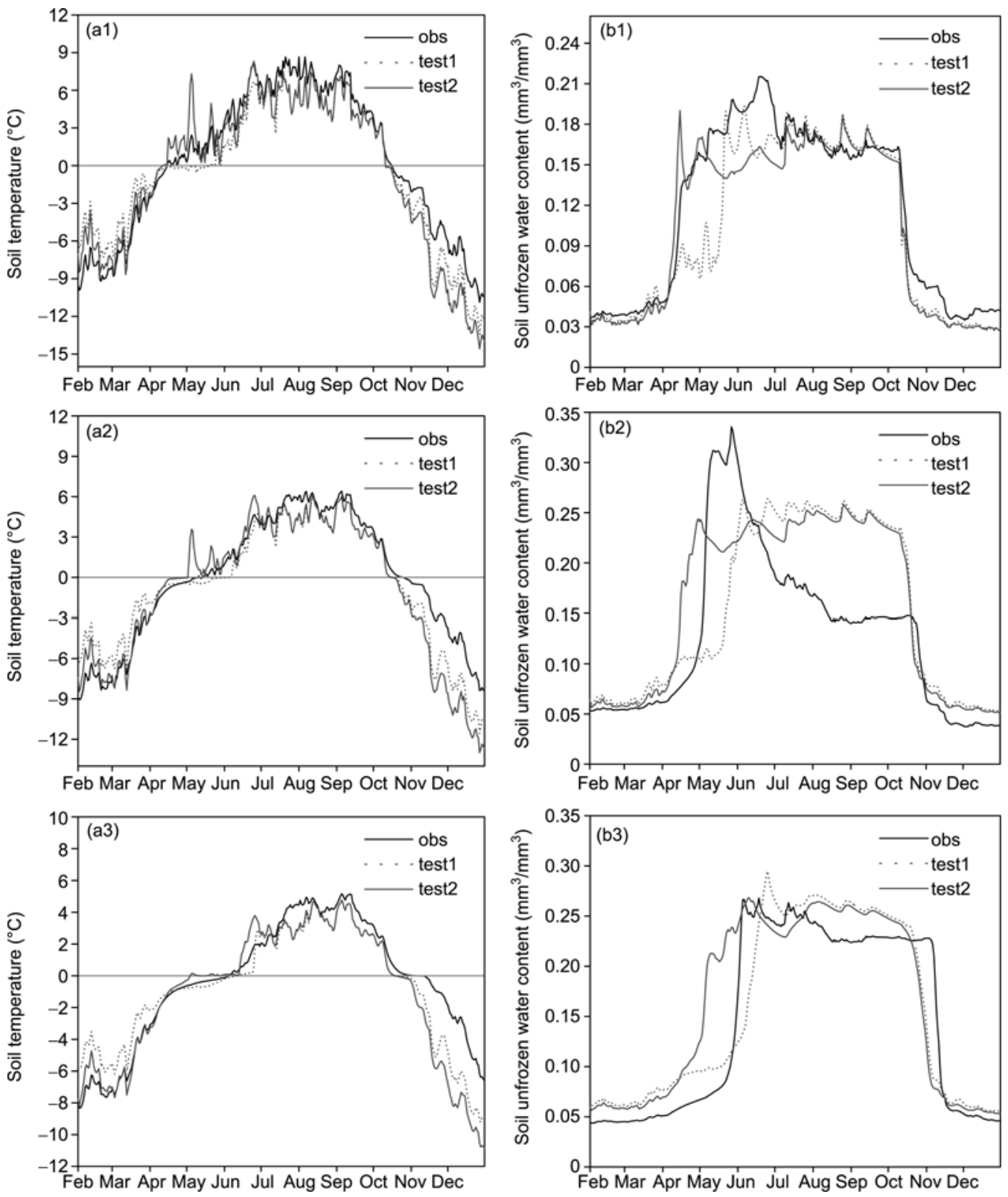

Figure 5 Comparison of observations (obs, heavy line) with soil temperature simulated with a change in the freeze-thaw critical temperature (test 1, dot line) and no change (test 2, fine line). The letter "a" in each figure represents the soil temperature and "b" stands for the soil liquid-water content. Numbers 1 , 2 and 3 represent the soil depths of 20,40 and $60 \mathrm{~cm}$, respectively.

rate is likely to be a change in the soil ice content. The heat conduction of ice is 4 times that of water, and the heat capacity of water is twice that of ice. Therefore, the change in soil ice content directly affects the upward and downward heat flux, and further affects the whole-system net energy. According to the calculation of soil temperature after phase change in CLM3.0 as introduced in section 3.1, we know that the net energy greatly affects the calculation of soil temperature. Changing the freezing rate affects the soil temperature, while it reveals the limitations of the algorithm used for the calculation of soil temperature in the case of a phase change. In the case of a phase change, it is difficult to obtain a numerical solution. We therefore suggest using the total enthalpy of soil and total quality of soil water as predictands to avoid the problem of obtaining a numerical solution.

\section{Discussion and conclusion}

The land-surface model CLM3.0 was employed to simulate the soil water and thermal processes at a site in Suli, Qinghai Province, from February 1 to December 31, 2009. The capability of the model was examined by comparing the 

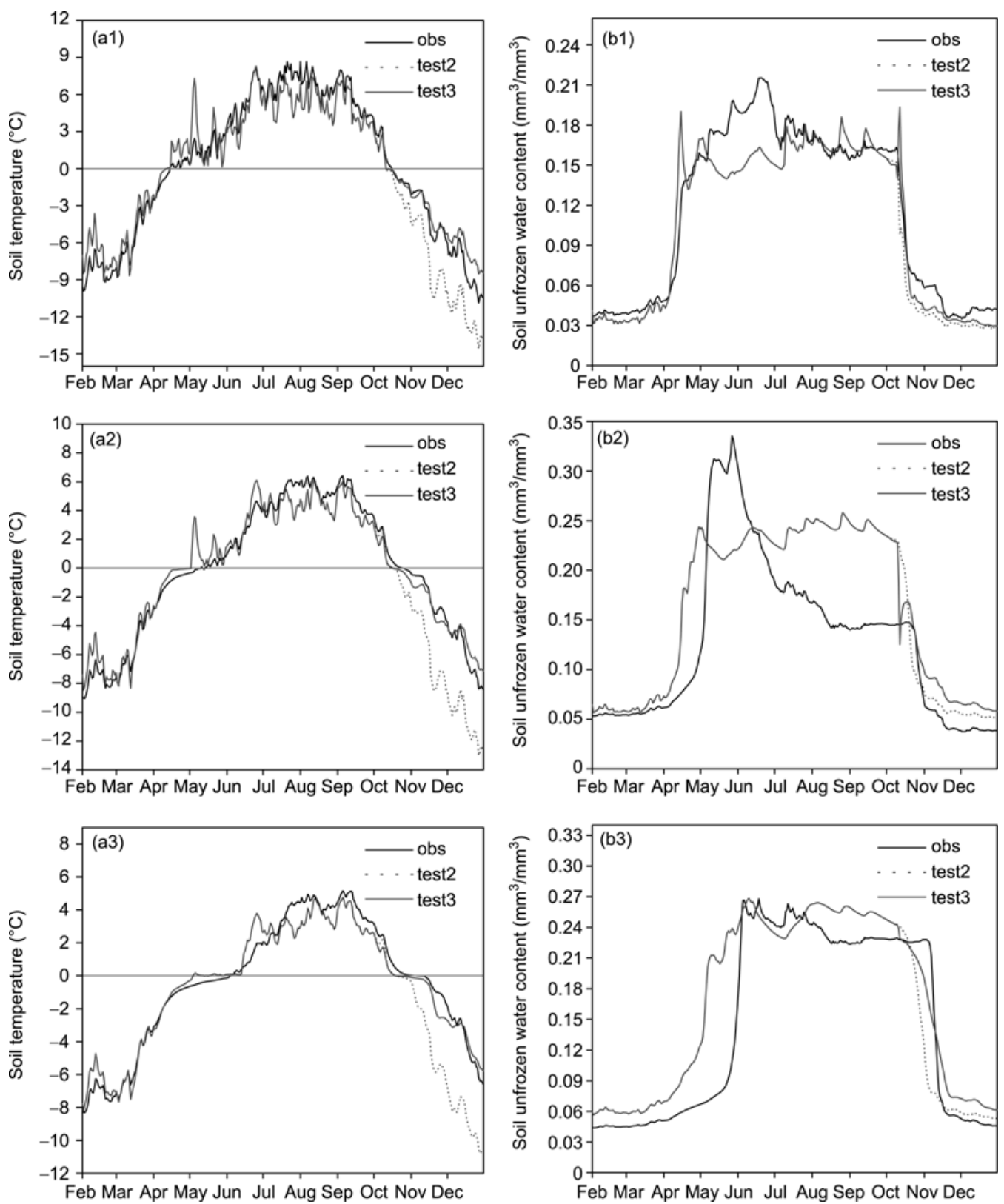

Figure 6 Comparison of observations (obs, heavy line) with soil temperature simulated with the modified freezing rate (test 2, dot line) and without (test 3, fine line) during the freezing period. The letter "a" in each figure represents the soil temperature and "b" indicates the soil liquid-water content. Numbers 1,2 and 3 represent soil depths of 20,40 and $60 \mathrm{~cm}$, respectively.

model results with observations. In addition, the critical freeze-thaw temperature was modified according to phase equilibrium equations. The following results were obtained.

(1) The exchange of soil water and heat was well simulated by CLM3.0. However, some limitations need to be addressed; e.g. the simulated soil temperature is higher than that observed and the ultimate thawing date is earlier than that observed during melting. The simulated soil temperature is a little lower than that observed and the ultimate freezing of deep soil is earlier than observed. Overall, the simulation of freezing is better than that of melting and the simulation of the shallow layer is better than that of deeper layers.

(2) The critical freeze-thaw temperature for certain liquid-water content can be calculated according to the phase equilibrium equation. With less liquid water content, the higher the sand content and the higher the critical freezethaw temperature, and vice versa. The critical freeze-thaw temperature approaches the freezing point as the liquid water content increases, but it is always below the freezing temperature.

(3) As the soil critical temperature for thawing decreases, the process of soil melting at a certain temperature below the freezing point is well simulated by CLM3.0. Because 
the frozen soil melts when the soil temperature is below $0^{\circ} \mathrm{C}$, the melting absorbs energy, and the thermal capacity of water is greater than that of ice, thus limiting the rate of increase in soil temperature and the rate of melting. The soil temperature simulated with the modified freeze-thaw scheme is thus lower than that obtained previously during the melting process, and the results are a closer match to observations.

(4) A sensitivity test shows that the freezing rate during freezing differs greatly from that during melting, with the former being lower than the latter, and the soil in the upper layers freezes more quickly than that in the lower layers. This provides a basis for improving the frozen-soil model in the future.

There are limitations to applying a land-surface model to plateau areas because of the complexity of terrain. The simulation of soil temperature and moisture has been notably improved using CLM3.0 with the modified freeze-thaw scheme. However, compared with observations, the simulated melting of shallow soil layers is slow, and the adjustment of the freezing rate is subjective, indicating that there are limitations to the calculation of soil temperature as phase change occurs. The occurrence of phase change makes it difficult to obtain a numerical solution. We therefore suggest using the total enthalpy of soil and the total quality of soil water as predictands to avoid the problem of obtaining a numerical solution. The numerical test was only carried out at a single point with the default surface dataset in this paper; therefore the observational soil properties were required and more tests should be carried out at different plateau stations and in various areas to enhance our understanding of the hydrothermal influence in cold regions.

The authors thank Ye Baisheng (CAREERI, CAS) for helping with field exploration and data collection and processing. Thanks are also due to Dr. Wang Jie (elder), Associate Research Fellow Wu Jinkui, Wang Jie (younger), Dr. Lu Yinhao, and anonymous reviewers for their comments on an earlier version of the manuscript. This work was supported by the National Basic Research Program of China (2007CB411505), the Major National Scientific Research Project on Global Changes (2010CB951902), and the National Natural Science Foundation of China (40975042 and 40905046).

1 Qin D H, Xiao C D, Ding Y J, et al. Progress on cryospheric studies by international and Chinese communities and perspectives (in Chinese). J Appl Meteoro Sci, 2006, 6: 649-656

2 Wang C H, Dong W J, Wei Z G. The development of study on the soil freezing-thaw progress in land surface model (in Chinese). Adv Earth Sci, 2002, 17: 44-52

3 Wang C H, Dong W J, Wei Z G. Study on relationship between the frozen-thaw progress in Qinghai-Xizang Plateau and circulation in East-Asia (in Chinese). Chinese J Geophys, 2003, 46: 310-312

4 Jin H J, Li S X, Wang S L, et al. Impacts of climatic change on permafrost and cold regions environments in China (in Chinese). Acta Geogr Sin, 2000, 55: 151-173

5 Wang S L, Zhao X F, Guo D X, et al. Response of permafrost to climate change in the Qinghai-Xizang Plateau (in Chinese). J Glaciol Geocryol, 1996, 18: 101-110

6 Jin $\mathrm{H} \mathrm{J}$, Cheng G D, Li X, et al. Permafrost on the Qinghai-Tibet
Plateau under a changing climate. Chinese Sci Bull, 1999, 44(S1): $152-158$

7 Li X, Cheng G D. The response model of permafrost frozen soil for global change in high altitude. Sci China Ser D-Earth Sci, 1999, 29: 185-192

8 Wang S W, Gong D Y. Western China Environmental Characteristics and Its Evolution (in Chinese). Beijing: Science Press, 2002. 1-248

9 Sun S F. The Physics, Biochemical Mechanism and Parameterization Model of Land Surface Model (in Chinese). Beijing: China Meteorological Press, 2005. 72-86

10 Xue Y, Zeng F J, Schlosser C A. SSiB and its sensitivity to soil properties-A case study using HAPEX-Mobilhy data. Glob Planet Change, 1996, 13: 183-194

11 Slater A G, Pitman A J, Desborough C E. Simulation of freeze-thaw cycles in a circulation model land surface scheme. J Geophys Res Atmos, 1998, 103: 11303-11312

12 Koren V, Schaake J, Mitchell K, et al. A parameterization of snow pack and frozen ground intended for NCEP weather and climate models. J Geophys Res-Atmos, 1999, 104: 19569-19585

13 Cherkauer K A, Lettenmaier D P. Hydrologic effects of frozen soils in the upper Mississippi River Basin. J Geophys Res-Atmos, 1999, 104: 19599-19610

14 Niu G Y, Yang Z L. Effects of frozen soil on snowmelt runoff and soil water storage at a continental scale. Bull Amer Meteorol Soc, 2006, 7: 937-952

15 Li Q, Sun S F. Development and modification of a coupled soil-waterheat transfer common land model (in Chinese). Sci China Ser DEarth Sci, 2007, 37: 1522-1535

16 Wang L N, Zheng Q L, Song Q L. Numerical simulation of the influences of west-central Qinghai-Xizang Plateau on East Asia seasonal transition (in Chinese). Plateau Meteorol, 2003, 22: 179-184

17 Li G P, Duan T Y, Gong Y F. The bulk transfer coefficients and surface fluxes on the western Tibetan Plateau. Chinese Sci Bull, 2000, 45: $1221-1226$

18 Henderson-Sellers A, Yang Z L, Dickinson R E. The project for intercomparison of land-surface parameterization schemes (PILPS). Bull Amer Meteorol Soc, 1993, 74: 1335-1349

19 Henderson-Sellers A, McGuffie K, Pitman A J. The project for intercomparison of land-surface parameterization schemes (PILPS): 1992 to 1995 . Clim Dyn, 1996, 12: 849-859

20 Wood E F, Lettenmaier D, Liang X, et al. The project for inter-comparison of land-surface parameterization schemes (PILPS) Phase-2c Red-Arkansa River Basin experiment: 1. Experiment description and summary inter-comparisons. Glob Planet Change, 1998, 19: 115-135

21 Huang W, Guo Z H, Yu R C. Numerical simulation of CLM over Huaihe basin. Acta Meteorol Sin, 2004, 62: 764-775

22 Liu S F, Lin Z H. Validation of common land model using field experiment data over typical land cover types in East Asia (in Chinese). Clim Environ Res, 2005, 10: 684-699

23 Lu Q F. Infulence of land surface boundary conditions (such as LAI) on the regional climate simulation and preparation of land surface remotely-sensed parameters for regional climate model $(\mathrm{CWRF}+$ CLM) (in Chinese). Dissertation for the Dotoral Degree. Nanjing: Nanjing University of Information Science \& Technology, 2006. $1-138$

24 Zou L J. Atmospheric forcing data assilimation for CLM and its application in China (in Chinese). Dissertation for the Doctoral Degree. Nanjing: Nanjing University of Information Science \& Technology, 2007. 42-51

25 Xin Y F, Bian L G, Zhang X H. The application of CoLM to arid region of northwest China and Qinghai-Xizang Plateau (in Chinese). Plateau Meteor, 2006, 25: 567-574

26 Wang C H, Shi R, Zuo H C. Analysis on simulation of characteristic of land surface in western Qinahai-Xizang Plateau during frozen and thawing (in Chinese). Plateau Meteorol, 2008, 27: 239-248

27 Luo S Q, Lv S H, Zhang Y, et al. Simulation analysis on land surface progress of BJ site of central Tibetan Plateau using CoLM (in Chinese). Plateau Meteorol, 2008, 27: 259-271

28 Deardorff J W. Efficient prediction of ground surface temperature 
and moisture, with inclusion of a layer of vegetation. J Geophys Res, 1978, 83: 1889-1903

29 Su F G, Hao Z C. Review of land-surface hydrological progress parameterization. Adv Earth Sci, 2001, 16: 795-800

30 Oleson K W, Dai Y J, Bonan G, et al. Technical description of the Community Land Model (CLM). Tech. Note NCAR/TN-461+STR, 2004

31 Oleson K W, Lawrence D M, Bonan G B, et al. Technical description of version 4.0 of the Community Land Model (CLM), NCAR Technical Note NCAR/TN-478+STR, 2010

32 Zhou S Q, Zhang C, Wang X N, et al. Simulation of soil temperature with a multi-layer model and its verification (in Chinese). J Nanjing Inst Meteor, 2004, 27: 200-209

33 Xu X Z, Wang J C, Zhang L X. Physics of Frozen Soil (in Chinese). Beijing: Science Press, 2001. 110-115

34 Ma Z G, Wei H L, Fu C B. Progress in the research on the relation- ship between soil moisture and climate change (in Chinese). Adv Earth Sci, 1999, 14: 290-305

35 Spaans E J, Baker J M. The soil freezing characteristic: Its measurement and similarity to the soil moisture characteristic. Soil Sci Soc Amer J, 1996, 60: 13-19

36 Huang H F. The Mechanism and Simulation of Interaction Between Soil, Vegetation and Atmosphere (in Chinese). Beijing: China Meteorological Press, 1997. 122-135

37 Li Q. Development of the universal and simplified soil model coupling heat and water transport (in Chinese). Dissertation for the Doctoral Degree. Beijing: Institute of Atmospheric Physics, Chinese Academy of Sciences, 2008. 33-45

38 Zhang X. The study of land surface model on arid and cold region-model improvement (in Chinese). Dissertation for the Doctoral Degree. Beijing: Institute of Atmospheric Physics, Chinese Academy of Sciences, 2004. 50-82

Open Access This article is distributed under the terms of the Creative Commons Attribution License which permits any use, distribution, and reproduction in any medium, provided the original author(s) and source are credited. 